\title{
Synergism of the AMPA-antagonist NBQX and the NMDA-antagonist CPP with L-Dopa in models of Parkinson's disease
}

\author{
P.- A. Löschmann ${ }^{2}$, K. W. Lange ${ }^{1}$, M. Kunow ${ }^{2}$, K.- J. Rettig ${ }^{2}$, P. Jähnig ${ }^{4}$, T. Honoré ${ }^{5}$, \\ L. Turski ${ }^{2}$, H. Wachtel ${ }^{2}$, P. Jenner ${ }^{1}$, and C. D. Marsden ${ }^{3}$ \\ ${ }^{1}$ Parkinson's Disease Society Experimental Research Laboratories, Pharmacology Group, \\ Biomedical Sciences Division, King's College, London, United Kingdom \\ ${ }^{2}$ Research Laboratories, Schering AG, Berlin, Federal Republic of Germany \\ ${ }^{3}$ University Department of Clinical Neurology, Institute of Neurology, The National \\ Hospital, London, United Kingdom \\ ${ }^{4}$ A F B Comstat GmbH, Berlin, Federal Republic of Germany \\ ${ }^{5}$ CNS Division, Novo Nordisk A/S, Soeborg, Denmark
}

Accepted June 19, 1991

Summary. Degeneration of dopaminergic nigrostriatal neurons in Parkinson's disease results in an overactivity of excitatory glutamatergic projections from the subthalamic nucleus to the output nuclei of the basal ganglia resulting in rigidity and akinesia. In theory pharmacological blockade of these overactive systems should improve parkinsonian symptomatology. The selective AMPAantagonist NBQX and the competitive NMDA-antagonist CPP are not effective in animal models of Parkinson's disease when given alone but ameliorate parkinsonian symptomatology and stimulate locomotor activity when co-administered with a threshold dose of L-Dopa. These synergistic effects are seen in the MPTP-treated (1-methyl-4-phenyl-1,2,3,6-tetrahydropyridine) common marmoset and the rat with unilateral 6-hydroxydopamine (6-OHDA) lesions of the substantia nigra. Therefore competitive NMDA and non-NMDA antagonists may offer a new therapeutic strategy for the treatment of Parkinson's disease.

Keywords: L-Dopa, CPP, NMDA antagonist, NBQX, AMPA antagonist, MPTP, common marmosets, locomotor activity, Parkinsonism.

\section{Introduction}

Amino acids such as L-glutamate or L-aspartate are excitatory transmitters in the mammalian central nervous system (Fonnum, 1984). Their synaptic re- 
sponses are mediated by different receptor subtypes, three of which are coupled to ionophores. They are activated preferentially by N-methyl-D-aspartate (NMDA), quisqualate (QUIS) or $\alpha$-amino-3-hydroxy-5-methyl-4-isoxazolepropionate (AMPA) and kainate (KAIN), respectively. Neurodegenerative conditions such as Alzheimer's, Parkinson's and Huntington's diseases or amyotrophic lateral sclerosis may be related to dysfunction of glutamatergic systems (Olney, 1989). This assumption is based on the observation that L-glutamate itself (Olney, 1969) and compounds activating major glutamate receptor subtypes such as NMDA, kainate and AMPA/QUIS have neurotoxic properties and can produce excitotoxic lesions reminiscent of human neurodegenerative disorders. Furthermore $\mathrm{MPP}^{+}$-induced (1-methyl-4-phenyl-pyridinium ion) degeneration of dopaminergic cells in the substantia nigra can be prevented by competitive antagonists and non-competitive antagonists of the NMDA-receptors as we have shown recently (Turski et al., 1991). Cortical excitatory glutamatergic pathways innervate the caudate nucleus, putamen and the subthalamic nucleus of the basal ganglia (Carpenter, 1981). Dopaminergic projections arising from the substantia nigra pars compacta terminate in the caudate nucleus and putamen. The degeneration of dopaminergic nigrostriatal neurons in Parkinson's disease results in an overactivity of the internal segment of the pallidum, the substantia nigra pars reticulata and the subthalamic nucleus. The excitatory glutamatergic projection from the subthalamic nucleus to the pallidal output nuclei of the basal ganglia is overactive in experimental models of Parkinson's disease (Bergman et al., 1990) resulting in rigidity and akinesia. Based on these considerations a benefical effect of glutamate antagonists in Parkinson's disease has been proposed (Olney et al., 1987; Klockgether and Turski, 1989).

Inhibition of NMDA-receptors by the non-competitive antagonist MK-801 $((+)$-5-methyl-10,11-dihydro-5H-dibenzo[a,d]-cyclohepten-5,10-imine), as well as by the competitive antagonist CPP $(3-(( \pm)-2$-carboxypiperazin-4-yl)propyl-1-phosphonic acid) restores locomotor activity and reduces muscular rigidity in catecholamine-depleted mice (Carlsson and Carlsson, 1989) and rats (Klockgether et al., 1990). This effect is enhanced by concomitant treatment with L-Dopa (Klockgether and Turski, 1990). In the unilaterally 6-OHDA lesioned rat MK-801 has synergistic effects on rotations induced by either LDopa or the dopamine D-1 agonist SKF 38393 (Morelli and Di Chiara, 1990). The L-Dopa potentiating effects of MK- 801 and CPP indicate the potential usefulness of NMDA-antagonists for the treatment of Parkinson's disease. This assumption is substantiated by the fact that memantine, a derivative of the antiparkinsonian agent amantadine, has NMDA-antagonistic properties (Kornhuber et al., 1989). However, because of the lack of potent and selective antagonists, much less is known about the role of AMPA receptors in experimental models of Parkinson's disease. NBQX (6-nitro-7-sulfamoylbenzo[f] quinoxaline-2,3(1H,4H)-dione) is the most selective AMPA-antagonist described so far with an acceptable central bioavailability (Sheardown et al., 1990). This compound thus offers the opportunity to test the hypothesis that 
AMPA-receptors are involved in the mediation of excitatory basal ganglia outputs and could therefore provide a new target for the treatment of Parkinson's disease. Indeed, NBQX reverses muscular rigidity and akinesia in monoamine-depleted rats and MPTP-treated primates (Klockgether, personal communication). The present experiments were designed to compare the antiakinetic properties of NBQX with those of CPP in a rodent model of selective dopamine depletion and to investigate whether the AMPA-antagonist NBQX and the NMDA-antagonist CPP are also effective in a primate model of Parkinson's disease when combined with L-Dopa.

\section{Material and methods}

\section{Drugs and solutions}

The following compounds were employed: NBQX (6-Nitro-7-sulfamoylbenzo[f]quinoxaline-2,3(1H,4H)-dione sodium salt; Novo Nordisk $\mathrm{A} / \mathrm{S})$, benserazide hydrochloride (Hoffmann-La Roche, Switzerland), L-Dopa (L-3,4-dihydroxyphenylalanine, Sigma U.S.A) and CPP (3-(( \pm$)-2$-carboxypiperazin-4-yl)-propyl-1-phosphonic acid, Research Biochemicals, USA). CPP, L-Dopa, and benserazide were dissolved in sterile physiological saline and NBQX suspended in sterile physiological saline containing $10 \%(\mathrm{v} / \mathrm{w})$ polyethoxylated castor oil (Cremophor, BASF, FRG). All solutions were prepared immediately before administration and injected in a volume of $1 \mathrm{ml} / \mathrm{kg}$ body weight (monkey studies) or $5 \mathrm{ml} / \mathrm{kg}$ body weight (rat studies). All dosages refer to the free basé.

\section{Rat studies}

Male Wistar rats (Dept. Animal Breeding, Schering AG) weighing 390-510g, aged 10 months were housed in groups of 4 under standard conditions at a temperature of $22^{\circ}$ $\left( \pm 1^{\circ} \mathrm{C}\right)$ using a 12 hour light-dark cycle (light on from $6.00-18.00 \mathrm{~h}$ ).

\section{Stereotaxic surgery}

$16 \mu \mathrm{g} 6$-OHDA HCL (Sigma, USA) dissolved in $4 \mu \mathrm{l}$ physiological saline containing $0.02 \%$ ascorbic acid was injected into the left substantia nigra under pentobarbital anaesthesia (Nembutal $50 \mathrm{mg} / \mathrm{kg}$ ) 8 months prior to the experiment. The coordinates were: AP 1.9; L 1.8; AP - 2.1 according to a stereotaxic atlas (König and Klippel, 1963).

\section{Measurement of rotations}

Ipsiversive and contraversive rotations were registered by means of an automatic device consisting of 8 perspex bowls $(40 \mathrm{~cm}$ diameter) and electro-mechanical transducer systems. The latter registered a count (rotation) each time the animal rotated through 36 degrees. The number of rotations were accumulated in 10 min intervals and recorded for $120 \mathrm{~min}$. Only contraversive rotations were analysed since the number of ipsiversive rotations remained unaffected in all groups.

\section{Drug treatments}

2 or 6 months following injection of 6-OHDA into the left substantia nigra, 24 or 42 rats were randomly divided into groups of 6 animals treated with either vehicle, NBQX, benserazide followed by L-Dopa, or benserazide followed by L-dopa and NBQX. In a second 
experiment L-Dopa and benserazide were combined with CPP. See figure legends for treatment schedules.

\section{Statistical analysis}

The means \pm S.E.M. were calculated for time courses and accumulated rotation counts of the different treatment groups. Statistical differences were calculated for rotation counts accumulated over $120 \mathrm{~min}$ by an analysis of variance followed by a Tukey test.

\section{Monkey studies}

Common marmosets (Callithrix jacchus) of either sex weighing $280-420 \mathrm{~g}$, aged 6-8 years were housed either in pairs or alone under standard conditions at a temperature of $27^{\circ}$ $\left( \pm 1^{\circ} \mathrm{C}\right.$ ) and $50 \%$ relative humidity using a 12 hour light-dark cycle (light on from $6.00-$ $18.00 \mathrm{~h})$.

\section{MPTP-treatment}

The animals were treated with MPTP (1-methyl-4-phenyl-1,2,3,6-tetrahydropyridine hydrochloride; Schering AG) in doses of $2 \mathrm{mg} / \mathrm{kg}$ s.c. daily for up to 6 days. Since the response of individual animals differed markedly, variable dose regimens were applied to obtain comparable initial motor deficits. The cumulative doses administered ranged between 8 $12 \mathrm{mg} / \mathrm{kg}$. Following MPTP treatment the animals recovered from acute effects over a period of some weeks. During the following 6 months a further gradual recovery from the MPTP effects was observed. Prior to behavioural testing all animals showed a reduction of basal locomotor activity and exhibited slower and less coordinated movements, reduced checking movements of the head and eye blinks, as well abnormal postures of some parts of the body.

\section{Measurment of locomotor activity}

Locomotor activity of individual animals was measured simultaneously in four aluminium cages $(50 \times 60 \times 70 \mathrm{~cm})$ with stainless steel grid doors $(50 \times 70 \mathrm{~cm})$ identical to the animal's home cage but equipped with eight horizontally orientated sets of infrared photocells. The number of light beam interruptions due to the animal's movements were accumulated in $10 \mathrm{~min}$ intervals and recorded for $120 \mathrm{~min}$.

\section{Drug treatments}

6-8 months after exposure to MPTP a group of 4 animals was treated with either vehicle, NBQX. benserazide followed by L-Dopa or benserazide followed by L-Dopa and NBQX. In a second experiment L-Dopa and benserazide were combined with CPP. The treatments were repeated over the following weeks allowing a one week recovery period between experiments. A latin square design was used for the allocation of treatments. See figure legends for treatment schedules.

\section{Statistical analysis}

The means \pm S.E.M. were calculated for time courses and accumulated locomotor counts of the different treatment groups. Statistical differences were calculated for accumulated locomotor counts by the non-parametric Page test for ordered alternatives using exact distributions.

All animals experiments were carried out in accordance with the animal welfare guide- 
lines and laws of Great Britain (monkey studies) and the Federal Republic of Germany (rat studies), respectively.

\section{Results}

In a first series of experiments, 24 rats were injected with the neurotoxin 6OHDA into the left substantia nigra, 8 months prior to the testing of NBQX. All rats showed robust contraversive rotations when exposed to apomorphine and ipsiversive turns after amphetamine treatment consistent with unilateral destruction of dopamine neurones (data not shown). NBQX administered alone in a dose range from $0.1-12.5 \mathrm{mg} / \mathrm{kg}$ i.p. did not induce ipsiversive or contraversive rotations in the 6-OHDA-lesioned rats. Higher doses induced sedation so that ipsiversive and contraversive rotations fell below the level of vehicletreated controls (data not shown). A dose of $12.5 \mathrm{mg} / \mathrm{kg}$ i.p. NBQX was either given alone or in combination with a threshold dose of L-Dopa ( $25 \mathrm{mg} / \mathrm{kg}$ i.p.) after pretreatment with the peripheral decarboxylase inhibitor benserazide (100 mg/kg i.p.). L-Dopa alone induced slight rotation, whereas NBQX alone again reduced the response. However, the co-administration of both drugs led to a significant stimulation of tight nose to tail contraversive rotations (Fig. 1).

In a second series of experiments 42 rats were injected with 6-OHDA 2 months prior to testing of CPP. The animals were treated with vehicle of $\mathrm{L}$ Dopa (25 mg/kg i.p.) after pretreatment with benserazide $(100 \mathrm{mg} / \mathrm{kg}$ i.p.) alone or in combination with 5 doses of CPP $(0.025-6.25 \mathrm{mg} / \mathrm{kg}$ i.p.). CPP dosedependently added on to the effect of L-Dopa (Fig. 2) in a way that the rotations seen after $6.25 \mathrm{mg} / \mathrm{kg}$ i.p. in combination with L-Dopa were significantly different from treatment with L-Dopa alone.

Four common marmosets were rendered parkinsonian by subcutaneous administration of MPTP ( $2 \mathrm{mg} / \mathrm{kg}$ daily for up to 6 days) 6 months prior to testing. At the beginning of the study the animals had recovered from the acute effects of MPTP-treatment but still showed substantially reduced locomotor activity and other signs of motor impairment. In a design similar to the experiments in rats, the monkeys were treated with NBQX $(6.25 \mathrm{mg} / \mathrm{kg}$ i.p. $)$ and L-Dopa (20 mg/kg i.p.) plus benserazide ( $20 \mathrm{mg} / \mathrm{kg}$ i.p.). L-Dopa had no effect when given alone and NBQX reduced locomotor activity. Co-administration of both drugs led to amelioration of parkinsonian symptomatology followed by a significant stimulation of locomotor activity throughout the observation period, with a maximum effect 50-60 min following administration (Fig. $3 \mathrm{~A}$, B). The locomotor stimulation took the form of fast and well-coordinated movements without dyskinesia. In a second experiment all animals were treated with the same doses of L-Dopa and benserazide alone or in combination with 3 doses of NBQX $(0.39-6.25 \mathrm{mg} / \mathrm{kg})$. NBQX dose-dependently stimulated locomotor activity in parkinsonian monkeys (Fig. $3 \mathrm{C}, \mathrm{D}$ ).

The effects of CPP in the MPTP-model were tested in a third experiment with an identical design. All animals received the same doses of L-Dopa and benserazide alone or in combination with 3 doses of CPP $(0.1-1.56 \mathrm{mg} / \mathrm{kg}$ i.p.). 

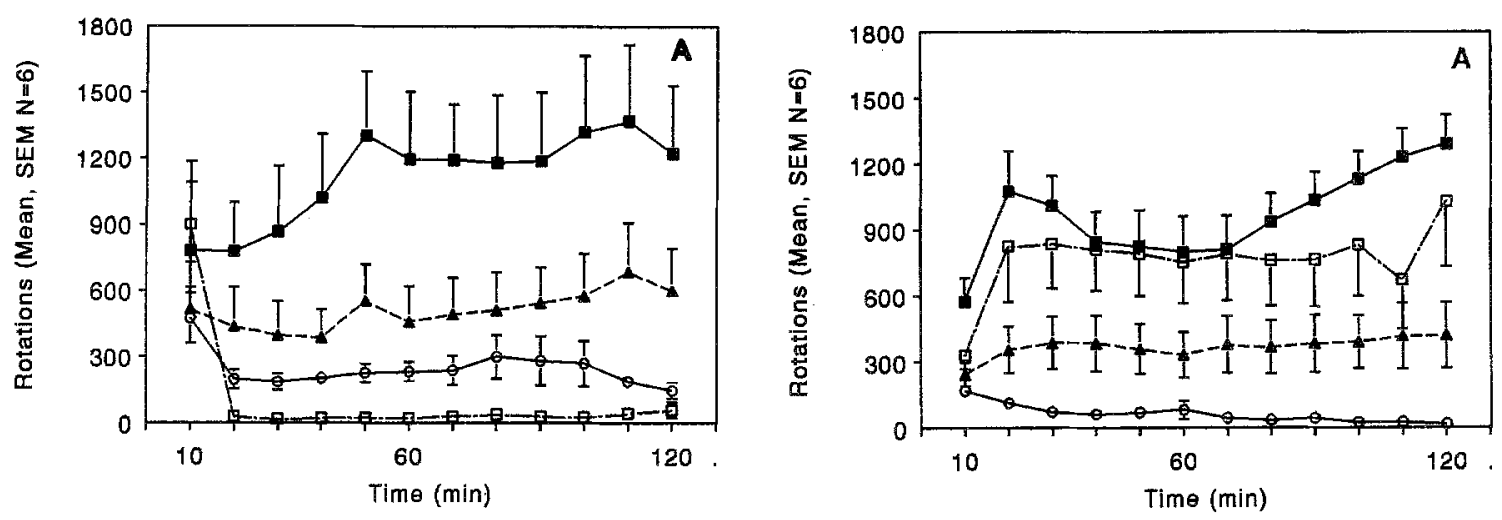

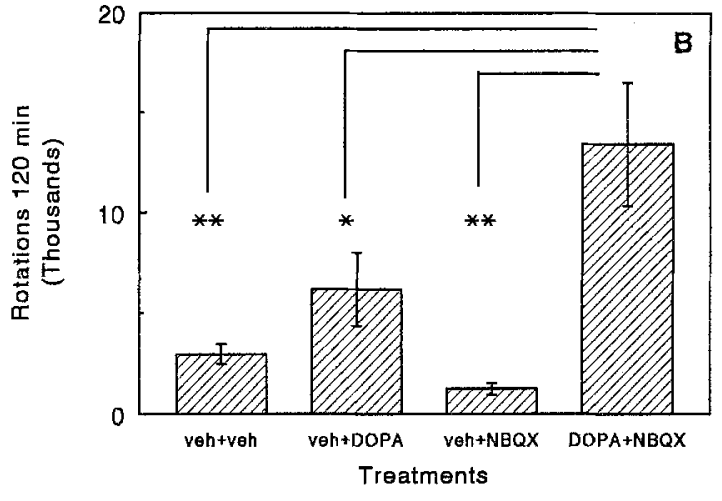

Fig. 1

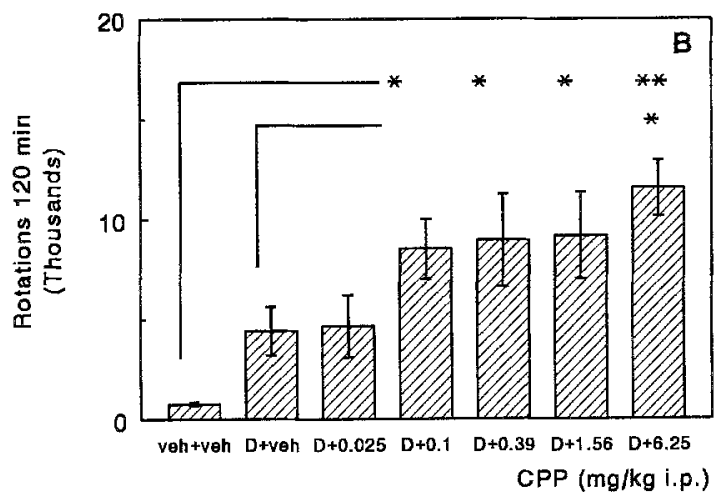

Fig. 2

Fig. 1. A Mean contraversive rotations ( $\pm \mathrm{SEM}, \mathrm{N}=6$ ) accumulated in 10 min intervals for $120 \mathrm{~min}$, of male rats with 6-OHDA lesions of the left substantia nigra, following treatment with (a) benserazide vehicle $15 \mathrm{~min}$ prior to L-Dopa vehicle and NBQX vehicle $\left(-\mathrm{O}^{-}\right)$, (b) $100 \mathrm{mg} / \mathrm{kg}$ benserazide i.p. $15 \mathrm{~min}$ prior to $25 \mathrm{mg} / \mathrm{kg}$ L-Dopa i.p. and vehicle $(-\mathbf{A}-)$, (c) vehicle $15 \mathrm{~min}$ prior to vehicle and $12.5 \mathrm{mg} / \mathrm{kg}$ NBQX i.p. $(-\square-)$, and (d) $100 \mathrm{mg} / \mathrm{kg}$ benserazide i.p. $15 \mathrm{~min}$ prior to $25 \mathrm{mg} / \mathrm{kg}$ L-Dopa i.p. and $12.5 \mathrm{mg} / \mathrm{kg} \mathrm{NBQX}$ i.p. $(-\mathbf{-}-)$, respectively. B Mean contraversive rotations ( \pm SEM) accumulated over $120 \mathrm{~min}$ for the data shown in A. NBQX administered alone suppressed rotations whereas a significant stimulation was seen with the combined treatment L-Dopa plus NBQX $\left({ }^{*} \mathrm{p}<0.05,{ }^{* *} \mathrm{p}<0.01\right.$, analysis of variance followed by a Tukey test)

Fig. 2. A Mean contraversive rotations ( $\pm S E M, N=6$ ) accumulated in 10 min intervals for $120 \mathrm{~min}$, of male rat with 6-OHDA lesions of the left substantia nigra, following treatment with (a) benserazide vehicle $15 \mathrm{~min}$ prior to L-Dopa vehicle and CPP vehicle ( $-\mathrm{O}-$ ), (b) $100 \mathrm{mg} / \mathrm{kg}$ benserazide i.p. $15 \mathrm{~min}$ prior to $25 \mathrm{mg} / \mathrm{kg}$ L-Dopa i.p. and vehicle (- $\Delta-$ ), (c) $100 \mathrm{mg} / \mathrm{kg}$ benserazide i.p. $15 \mathrm{~min}$ prior to $25 \mathrm{mg} / \mathrm{kg}$ L-Dopa i.p. and $1.56 \mathrm{mg} /$ $\mathrm{kg}$ CPP i.p. ( $\square-$ ), and (d) $100 \mathrm{mg} / \mathrm{kg}$ benserazide i.p. $15 \mathrm{~min}$ prior to $25 \mathrm{mg} / \mathrm{kg}$ L-Dopa i.p. and $6.25 \mathrm{mg} / \mathrm{kg}$ CPP i.p. $(-\mathbf{-}-)$, respectively. The data for the lower doses tested $(0.025,0.1$, and $0.39 \mathrm{mg} / \mathrm{kg} \mathrm{CPP}$ i.p.) are omitted for claritiy. The animals were pretreated and monitored as described in methods exept that 6-OHDA was injected 2 months prior to the experiment. B Mean contraversive rotations ( \pm SEM) accumulated over $120 \mathrm{~min}$ for the data shown in A and the lower doses tested. L-Dopa administered alone induced rotations. A significant stimulation was seen with the combined treatment L-Dopa plus CPP $0.1,0.39,1.56$, and $6.25 \mathrm{mg} / \mathrm{kg}$ i.p. The highest dose of CPP $(6.25 \mathrm{mg} / \mathrm{kg}$ i.p. $)$ was also significantly different from the group treated with L-Dopa alone $\left({ }^{*} \mathrm{p}<0.05, * * \mathrm{p}<0.01\right.$, analysis of variance followed by a Tukey test) 



Fig. 3. A Mean locomotor activity counts ( $\pm S E M, N=4$ ) accumulated in 10 min intervals for $120 \mathrm{~min}$, of MPTP-lesioned common marmosets treated with (a) benserazide vehicle $15 \mathrm{~min}$ prior to L-Dopa vehicle and NBQX vehicle $(-\mathrm{O}-$ ), (b) $20 \mathrm{mg} / \mathrm{kg}$ benserazide i.p. $15 \mathrm{~min}$ prior to $20 \mathrm{mg} / \mathrm{kg}$ L-Dopa i.p. and vehicle $(-\mathbf{A}-$ ), (c) vehicle $15 \mathrm{~min}$ prior to vehicle and $6.25 \mathrm{mg} / \mathrm{kg}$ NBQX i.p. (- $\square-$ ), and (d) $20 \mathrm{mg} / \mathrm{kg}$ benserazide i.p. $15 \mathrm{~min}$ prior to $20 \mathrm{mg} / \mathrm{kg} \mathrm{L-Dopa} \mathrm{i.p.} \mathrm{and} 6.25 \mathrm{mg} / \mathrm{kg}$ NBQX i.p. ( $-\mathbf{E}-)$, respectively. Error bars for control and L-Dopa treatments are left out for clarity but were within the same range as those shown in NBQX and L-Dopa plus NBQX. B Mean locomotor activity counts ( \pm SEM) accumulated over $120 \mathrm{~min}$ for the data shown in A. There was no difference between vehicle and L-Dopa treatment. However, NBQX adminstered alone reduced locomotor activity whereas a significant stimulation was seen with the combined treatment L-Dopa plus NBQX ( $p<0.05$, Page test, ordered alternative: NBQX $<$ L-Dopa $<$ L-Dopa plus NBQX). $C$ Mean locomotor activity counts ( $\pm \mathrm{SEM}, \mathrm{N}=4$ ) accumulated in $10 \mathrm{~min}$ intervals for $120 \mathrm{~min}$ of MPTP-lesioned common marmosets treated with (a) $20 \mathrm{mg} / \mathrm{kg}$ benserazide i.p. $15 \mathrm{~min}$ prior to $20 \mathrm{mg} / \mathrm{kg}$ L-Dopa i.p. and vehicle $(-\mathrm{O}-$ ), (b) $20 \mathrm{mg} / \mathrm{kg}$ benserazide i.p. $15 \mathrm{~min}$ prior to $20 \mathrm{mg} / \mathrm{kg}$ L-Dopa i.p. and $0.39 \mathrm{mg} / \mathrm{kg}$ NBQX i.p. ( - $\mathbf{A}-$ ), (c) $20 \mathrm{mg} / \mathrm{kg}$ benserazide i.p. $15 \mathrm{~min}$ prior to $20 \mathrm{mg} / \mathrm{kg} \mathrm{L-Dopa} \mathrm{i.p.} \mathrm{and} 1.56 \mathrm{mg} / \mathrm{kg} \mathrm{NBQX}$. i.p. ( $-\square-$ ), and (d) $20 \mathrm{mg} / \mathrm{kg}$ benserazide i.p. $15 \mathrm{~min}$ prior to $20 \mathrm{mg} / \mathrm{kg}$ L-Dopa i.p. and $6.25 \mathrm{mg} / \mathrm{kg} \mathrm{NBQX}$ i.p. $\left(-\mathbf{D}_{-}\right.$), respectively. Error bars for L-Dopa alone and $0.39 \mathrm{mg} /$ $\mathrm{kg}$ NBQX treatments are left out for clarity but were within the same range as those shown for $\mathbb{L}$-Dopa plus NBQX. D Mean locomotor activity counts ( \pm SEM) accumulated over $120 \mathrm{~min}$ for the data shown in C. Locomotor activity was significantly stimulated by the combined treatment L-Dopa plus NBQX $(p<0.01$, Page test, ordered alternative: LDopa $<$ L-Dopa plus NBQX $0.39<$ L-Dopa plus NBQX $1.56<$ L-Dopa plus NBQX 6.25) 

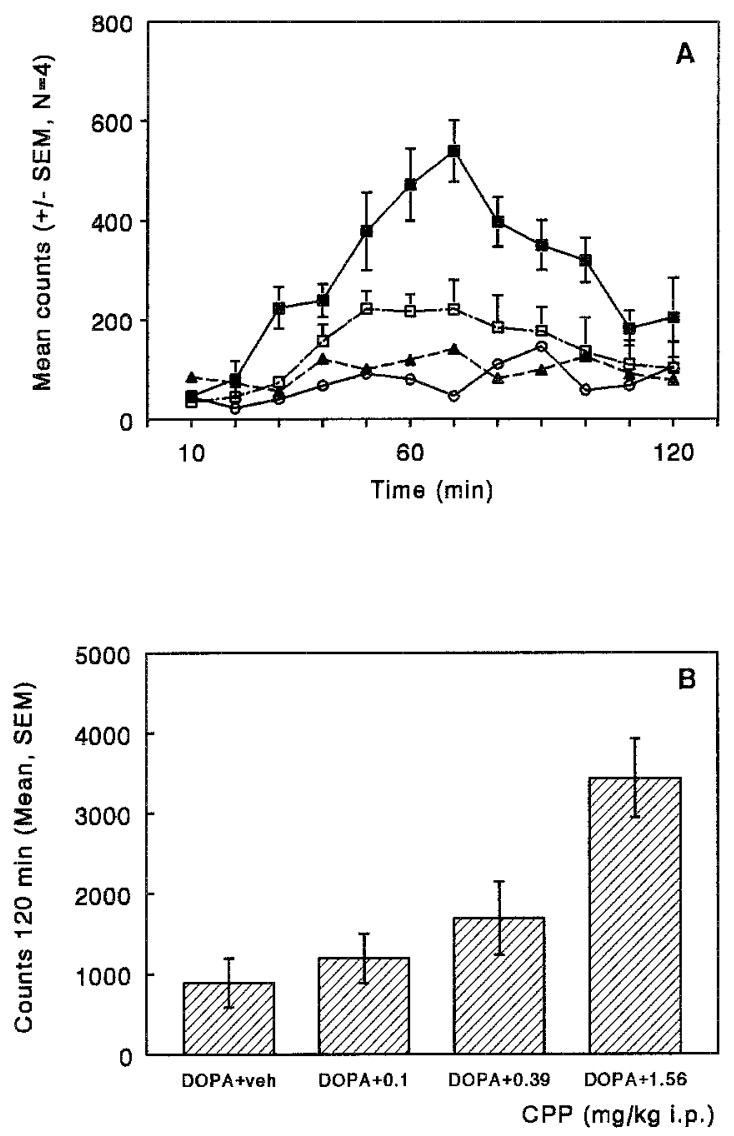

Fig. 4. A Mean locomotor activity counts ( \pm SEM, $N=4$ ) accumulated in 10 min intervals for $120 \mathrm{~min}$ of MPTP-lesioned common marmosets treated with (a) $20 \mathrm{mg} / \mathrm{kg}$ benserazide i.p. $15 \mathrm{~min}$ prior to $20 \mathrm{mg} / \mathrm{kg}$ L-Dopa i.p. and vehicle $(-\mathrm{O}-$ ), (b) $20 \mathrm{mg} / \mathrm{kg}$ benserazide i.p. $15 \mathrm{~min}$ prior to $20 \mathrm{mg} / \mathrm{kg}$ L-Dopa i.p. and $0.1 \mathrm{mg} / \mathrm{kg}$ CPP i.p. $(-\boldsymbol{\Lambda}-)$, (c) $20 \mathrm{mg} / \mathrm{kg}$ benserazide i.p. $15 \mathrm{~min}$ prior to $20 \mathrm{mg} / \mathrm{kg}$ L-Dopa i.p. and $0.39 \mathrm{mg} / \mathrm{kg}$ CPP i.p. $(-\square-)$, and (d) $20 \mathrm{mg} / \mathrm{kg}$ benserazide i.p. $15 \mathrm{~min}$ prior to $20 \mathrm{mg} / \mathrm{kg}$ L-Dopa i.p. and $1.56 \mathrm{mg} / \mathrm{kg}$ CPP i.p. (- - ), respectively. Error bars for L-Dopa alone and $0.1 \mathrm{mg} / \mathrm{kg}$ CPP treatments are left our for clarity but were within the same range as those shown for L-Dopa plus CPP. B Mean locomotor activity counts ( \pm SEM) accumulated over 120 min for the data shown in A. Locomotor activity was significantly stimualted by the combined treatment L-Dopa plus CPP ( $p<0.01$, Page test, ordered alternative: L-Dopa $<$ L-Dopa plus CPP $0.1<\mathrm{L}$ Dopa plus CPP $0.39<$ L-Dopa plus CPP 1.56).

CPP also had synergistic effects to a threshold dose of L-Dopa in the parkinsonian monkey (Fig. 4A, B). The movements in the highest dose tested were qualitatively not different from normal monkeys. Dyskinesia was not observed.

\section{Discussion}

Injection of 6-OHDA into the pars compacta of the substantia nigra of rats selectively depletes the ipsilateral striatum from endogenous dopamine (Un- 
gerstedt, 1968) and leads to denervation supersensitivity of postsynaptic dopamine receptors. Administration of apomorphine and amphetamine induces a characteristic turning response in this model. Inter alia this model has been used to identify potential antiparkinsonian drugs.

Administration of MPTP to man or non-human primates (Davis et al., 1979; Langston et al., 1983; Burns et al., 1983) including common marmosets (Jenner et al., 1984) induces a parkinsonian syndrome due to the selective destruction of nigrostriatal neurons, associated with a substantial decrease in dopamine content of the caudate nucleus and putamen. The deficits in motor performance produced by MPTP-treatment of common marmosets respond to classical antiparkinsonian drugs such as L-Dopa in combination with a peripheral decarboxylase inhibitor (Jenner et al., 1984), or dopamine receptor agonists such as $\mathrm{N}-0437$ (Löschmann et al., 1989). We therefore tested the effects of NBQX, CPP, and L-Dopa in this model.

In two independent models of Parkinson's disease in two species the AMPAantagonist NBQX had no antiparkinsonian activity when administered alone but dose-dependently potentiated the effects of a threshold dose of L-Dopa. Similarily the competitive NMDA-antagonist CPP had synergistic effects to LDopa in the 6-OHDA lesioned rat and the MPTP-treated monkey. These results are particularly important because the non-competitive NMDA-antagonist MK-801, although effective in rodent models of Parkinson's disease, was not active in the MPTP-treated common marmoset when administered alone (Close et al., 1990) and did not exert additive effects to L-Dopa in another primate species (Crossman et al., 1989) in the same model. In contrast, CPP (Crossman, personal communication) and the glutamate antagonist kynurenate reverse akinesia in the MPTP-treated common marmoset following focal injection into the medial pallidum (Brotchie et al., 1991). Lesion of the subthalamic nucleus by focal injection of the neurotoxin ibotenic acid also ameliorates parkinsonian symptomatology in MPTP-treated green monkeys (Bergman et al., 1990). These results indicate that the selective reduction of glutamatergic overactivity is an effective strategy for the treatment of Parkinson's disease. Since the glutamatergic thalamo-cortical tract seems to be underactive in Parkinson's disease (Bergman et al., 1990) systemic administration of glutamate antagonists should aggravate parkinsonian symptoms. This is probably reflected in the reduction of locomotor activity seen in MPTP-treated monkeys following NBQX given alone (Fig. 3 A, B). However, the results obtained with L-Dopa plus NBQX or CPP imply that stimulation of the deficient dopaminergic pathways in combination with an inhibition of the glutamatergic systems has clear synergistic effects on locomotor activity.

The MPTP-treated monkey currently appears to be the best pharmacological model of Parkinson's disease. Our results therefore indicate the potential usefulness of NBQX, and possibly other AMPA-antagonists, as well as competitive NMDA-antagonists such as CPP, for the symptomatic treatment of Parkinson's disease when combined with L-Dopa. We predict that such combined treatments 
should allow a reduction of the L-Dopa dose and thus could postpone or prevent side effects of long-term L-Dopa treatment (Marsden and Parkes, 1976). The non-competitive NMDA-antagonist MK-801 has unwanted side effects, such as induction of a psychosis in man (Troupin et al., 1986). Similarily, the amantadine derivative memantine, displacing $\left[{ }^{3} \mathrm{H}\right] \mathrm{MK}-801$ at nanomolar concentrations in binding assays (Kornhuber etal., 1991), induces pharmacotoxic psychosis in patients with Parkinson's disease at threshold doses required to elicit antiparkinsonian effects (Riederer et al., 1991). Whether non-NMDA antagonists such as NBQX or competitive NMDA-antagonists such as CPP have similar side effects remains to be tested in clinical trials.

\section{Acknowledgements}

K.W.L. was supported by the European Science Foundation and the European Medical Research Council.

\section{References}

Bergman H, Wichmann T, DeLong MR (1990) Reversal of experimental parkinsonism by lesions of the subthalamic nucleus. Science 249: 1436-1438

Brotchie JM, Mitchell IJ, Sambrook MA, Crossman A (1991) Alleviation of parkinsonism by antagonism of excitatory amino acid transmission in the medial segment of the globus pallidus in rat and primate. Movement Disorders 6: 133-138

Burns RS, Chiueh CC, Markey SP, Ebert MH, Jacobowitz DM, Kopin IJ (1983) A primate model of parkinsonism; selective destruction of dopaminergic neurons in the pars compacta of the substantia nigra by N-methyl-4-phenyl-1,2,3,6-tetrahydropyridine. Proc Natl Acad Sci USA 80: 4546-4550

Carlsson M, Carlsson A (1989) Dramatic synergism between MK-801 and clonidine with respect to locomotor stimulatory effect in monoamine-depleted mice. J Neural Transm 77: $65-71$

Carpenter MB (1981) Anatomy of the corpus striatum and brain stem integrating systems. In: Brooks VB (ed) Handbook of physiology, sect 1. The nervous system II. American Physiological Society, Bethesda, pp 947-995

Close SP, Elliot PJ, Hayes AG, Marriott AS (1990) Effects of classical and novel agents in a MPTP-induced reversible model of Parkinson's disease. Psychopharmacology 102: 295-300

Crossman AR, Peggs D, Boyce S, Luquin MR, Sambrook MA (1989) Effect of the NMDA antagonist MK-801 on MPTP-induced parkinsonism in the monkey. Neuropharmacology 28: 1271-1273

Davis GC, Williams AC, Markey SP, Ebert MH, Caine ED, Reichert CM, Kopin IJ (1979) Chronic parkinsonism secondary to intravenous injection of meperidine analogues. Psychiatry Res 1: 249-254

Fonnum F (1984) Glutamate: a neurotransmitter in mammalian brain. J Neurochem 42 : $1-11$

Jenner P, Rupniak NMJ, Rose S, Kelley E, Kilpatrick G, Lees A, Marsden CD (1984) 1-Methyl-4-phenyl-1,2,3,6-tetrahydropyridine-induced parkinsonism in the common marmoset. Neurosci Lett 50: 85-90

Klockgether T, Turski L (1989) Excitatory amino acids and the basal ganglia: implications for the therapy of Parkinson's disease. Trends Neurosci 12: 285-286

Klockgether T, Turski L (1990) NMDA antagonists potentiate antiparkinsonian actions of L-Dopa in monoamine-depleted rats. Ann Neurol 28: 539-546 
Klockgether T, Turski L, Löschmann P-A, Wachtel H (1990) N-Methyl-D-aspartate antagonists stimulate locomotor activity in monoamine depleted rats: implications for therapy of Parkinson's disease. In: Lubec G, Rosenthal GA (eds) Amino acids: chemistry, biology and medicine. ESCOM Science Publishers B.V, Leiden, pp 269-275

König JFR, Klippel RA (1963) The rat brain: a stereotaxic atlas of the forebrain and lower parts of the brain stem. William and Wilkins, Baltimore

Kornhuber J, Bormann J, Retz W, Hübers M, Riederer P (1989) Memantine displaces $\left[{ }^{3} \mathrm{H}\right] \mathrm{MK}-801$ at therapeutic concentrations in postmortem human frontal cortex. Eur J Pharmacol 166: 589-590

Kornhuber J, Bormann J, Hübers M, Rusche E, Riederer P (1991) Effects of the 1-aminoadamantanes at the MK-801-binding site of the NMDA-receptor-gated ion channel: a human postmortem brain study. Eur J Pharmacol (Mol Pharmacol Sect) 206: 297300

Langston JW, Ballard B, Tetrud JW, Irwin I (1983) Chronic parkinsonism in humans due to a product of meperidineanalog synthesis. Science 225: 1480-1482

Löschmann P-A, Chong PN, Nomoto M, Tepper PG, Horn AS, Jenner P, Marsden CD (1989) Stereoselective reversal of MPTP-induced parkinsonism in the marmoset after dermal application of N-0437. Eur J Pharmacol 166: 373-380

Marsden CD, Parkes JD (1976) 'On-off' effects in patients with Parkinson's disease on chronic levodopa therapy. Lancet i: 292-296

Morelli M, Di Chiara G (1990) MK-801 potentiates dopaminergic $D_{1}$ but reduces $D_{2}$ responses in the 6-hydroxydopamine model of Parkinson's disease. Eur J Pharmacol 182: $611-612$

Olney JW (1969) Brain lesions, obesity and other disturbances in mice treated with monosodium glutamate. Science 164: 719-721

Olney JW, Price MT, Labruyere J, Salles KS, Frierdich G, Mueller M, Silverman E (1987) Anti-parkinsonian agents are phencyclidine agonists and N-methyl-aspartate antagonists. Eur J Pharmacol 142. 319-320

Olney JW (1989) Excitotoxicity and N-methyl-D-aspartate receptors. Drug Dev Res 17: 299-319

Riederer R, Kornhuber J, Gerlach M, Danielczyk W, Youdim MBH (1991) Glutamatergicdopaminergic imbalance in Parkinson's disease and paranoid hallucinatory psychosis. In: Rinne UK, Nagatsu T, Horowski R (eds) Proceedings International Workshop Parkinson's Disease: from Basic Research and Early Diagnosis to Long-Term Treatment. Medicom Europe BV, Bussum The Netherlands (in press)

Sheardown MJ, Nielsen EO, Hansen AJ, Jacobsen P, Honoré T (1990) 2,3-Dihydroxy-6nitro-7-sulfamoyl-benz(F)quinoxaline: a neuroprotectant for cerebral ischaemia. Science 247: 571-574

Troupin AS, Mendius JR, Cheng F (1986) MK 801. In: Meldrum BS, Potter RJ (eds) Current problems in epilepsy 4. New anticonvulsant drugs. John Libbey, London, pp 191-201

Turski L, Bressler K, Rettig K-J, Löschmann P-A, Wachtel H (1991) Protection of substantia nigra from $\mathrm{MPP}^{+}$neurotoxicity by $\mathrm{N}$-methyl-D-aspartate antagonists. Nature 349: $414-418$

Ungerstedt $U$ (1968) 6-Hydroxydopamine induced degeneration of central monoamine neurons. Eur J Pharmacol 5: 107-110

Authors' address: Dr. P. A. Löschmann, Department of Neuropsychopharmacology, Schering AG, P.O.B. 6503 11, D-W-1000 Berlin 65, Federal Republic of Germany 